\title{
Prevalence of Dry Eye Disease and Quality of Life Associations in Pre-operative Cataract Patients
}

\section{$\sqrt{\text { VEc COTOR }}$}

\section{INTRODUCTION}

Perioperative Dry Eye Syndrome (DES) and Meibomian Gland Dysfunction (MGD) are highly prevalent and important ocular conditions that can lead to visual dysfunction and varying degrees of disability following cataract surgery. ${ }^{1,2}$

Many patients experience foreign body sensation, light sensitivity, eye irritation, and blurred vision related to DES and MGD following cataract surgery. ${ }^{1,2}$

Objective physiologic and biochemical parameters related to ocular surface disease have been developed including 1) grading of MGD by meibography and 2) tear osmolarity. ${ }^{1,2,3}$

\section{OBJECTIVE}

To evaluate the prevalence of dry eye disease including tear osmolarity, meibomian gland dysfunction (MGD) and quality of life parameters associated with persistent dry eye symptoms prior to cataract surgery.

\section{METHODS}

- Retrospective analysis of seventy (70) eyes of thirty-five (35) patients presenting for pre-operative cataract surgery assessment at a single practice

- All eyes underwent tear osmolarity testing and screening lower eyelid meibography with grading of MGD based on percentage of structurally normal glands, shortened glands, lost glands and early obstructed glands

- Patients also completed a dry eye survey which quantifies symptom frequency, symptom severity and vocational severity

- Patients were categorized into 3 groups based on dry eye survey scores to a maximum total of 87 points as one of:

- mild (1-29)

- moderate (30-58)

- severe (59-87)

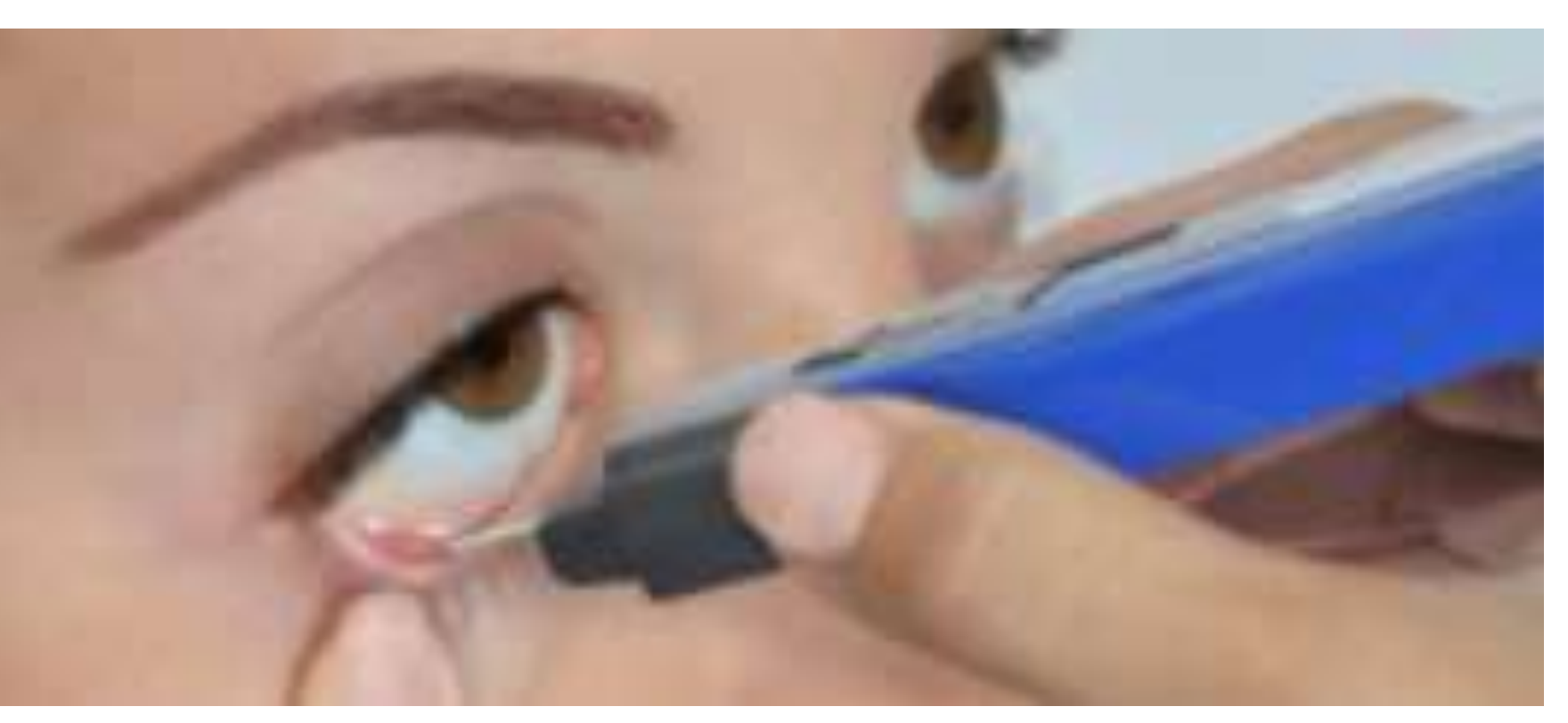

D. Moroz, ${ }^{1}$ A. Maddigan, ${ }^{2}$ J. Bhamra1,2

University of Calgary, Section of Ophthalmology VVector Eye Centre
UNIVERSITY OF CALGARY CUMMING SCHOOL OF MEDICINE

\section{RESULTS}

- The overall mean tear osmolarity for 70 eyes of 35 patients was 308 $\pm 2.0 \mathrm{mOsms} / \mathrm{L}$ and the mean dry eye survey score was $32 \pm 2.9$ - Meibography, expressed as a percentage of total glands in the lowe eyelid involved, revealed $49.5 \pm 3.3$ as structurally normal; $12.4 \pm$

1.5 obstructed; $19.6 \pm 3.0$ truncated; $13.3 \pm 2.6$ atrophic

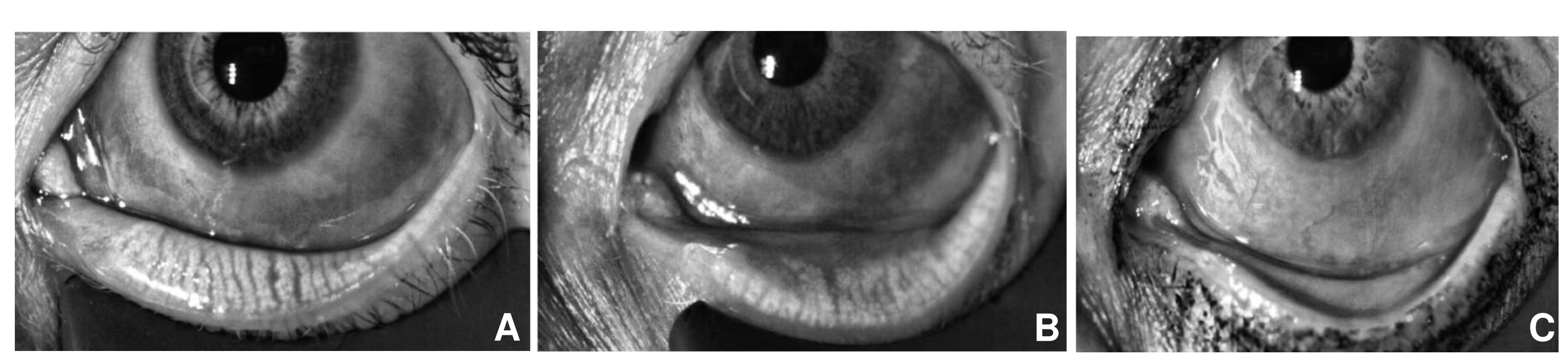

Figure 2. Meibography showing mild (A), moderate (B), and severe (C) meibomian gland truncation and loss.

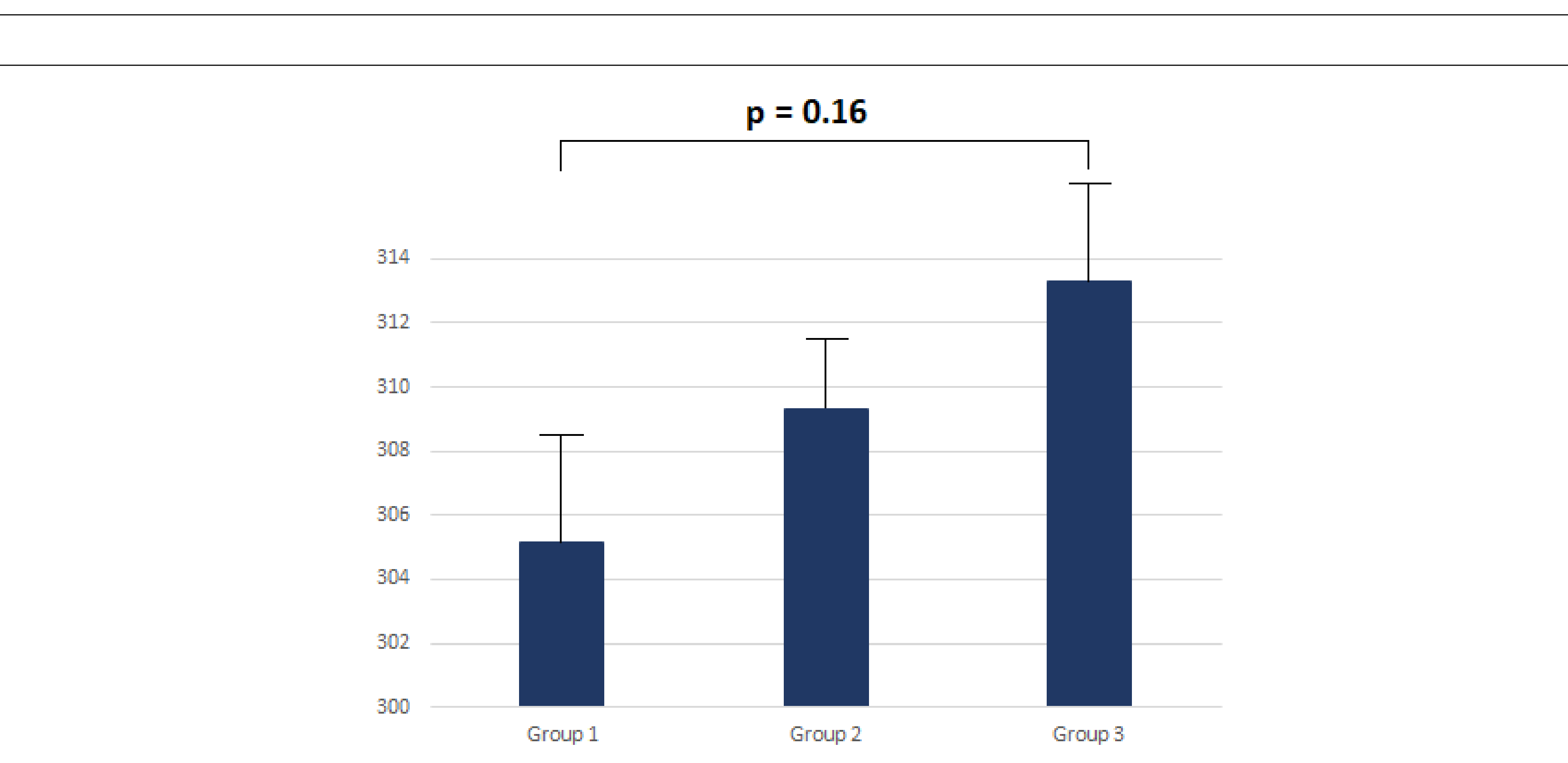

Figure 3. Comparison of mean tear osmolarity in $\mathrm{mOsms} / \mathrm{L}$ ( $\pm \mathrm{SE}$ ).

- Group 1 (Mild): the mean tear osmolarity for 32 eyes of 16 patients was $305 \pm 4.4 \mathrm{mOsms} / \mathrm{L}$. The mean dry eye survey score was $17 \pm$ 1.9. Meibography revealed $49.4 \pm 4.5 \%$ as structurally normal. - Group 2 (Moderate): the mean tear osmolarity for 32 eyes of 16 patients was $309 \pm 2.4 \mathrm{mOsms} / \mathrm{L}$. The mean dry eye survey score was $41.1 \pm 2.1$. Meibography revealed $51.1 \pm 5.0 \%$ as structurally normal.

- Group 3 (Severe): the mean tear osmolarity for 6 eyes of 3 patients was $313 \pm 6.5 \mathrm{mOsms} / \mathrm{L}$. The mean dry eye survey score was $64 \pm$ 2.5. Meibography revealed $41.7 \pm 14 \%$ as structurally normal. - The mean difference in tear osmolarity between the categories of mild vs. severe was $8.2 \mathrm{mOsms} / \mathrm{L}(p=0.15)$; and meibography as a percentage of normal glands between the categoies of mild vs. severe was $7.7(p=0.30)$

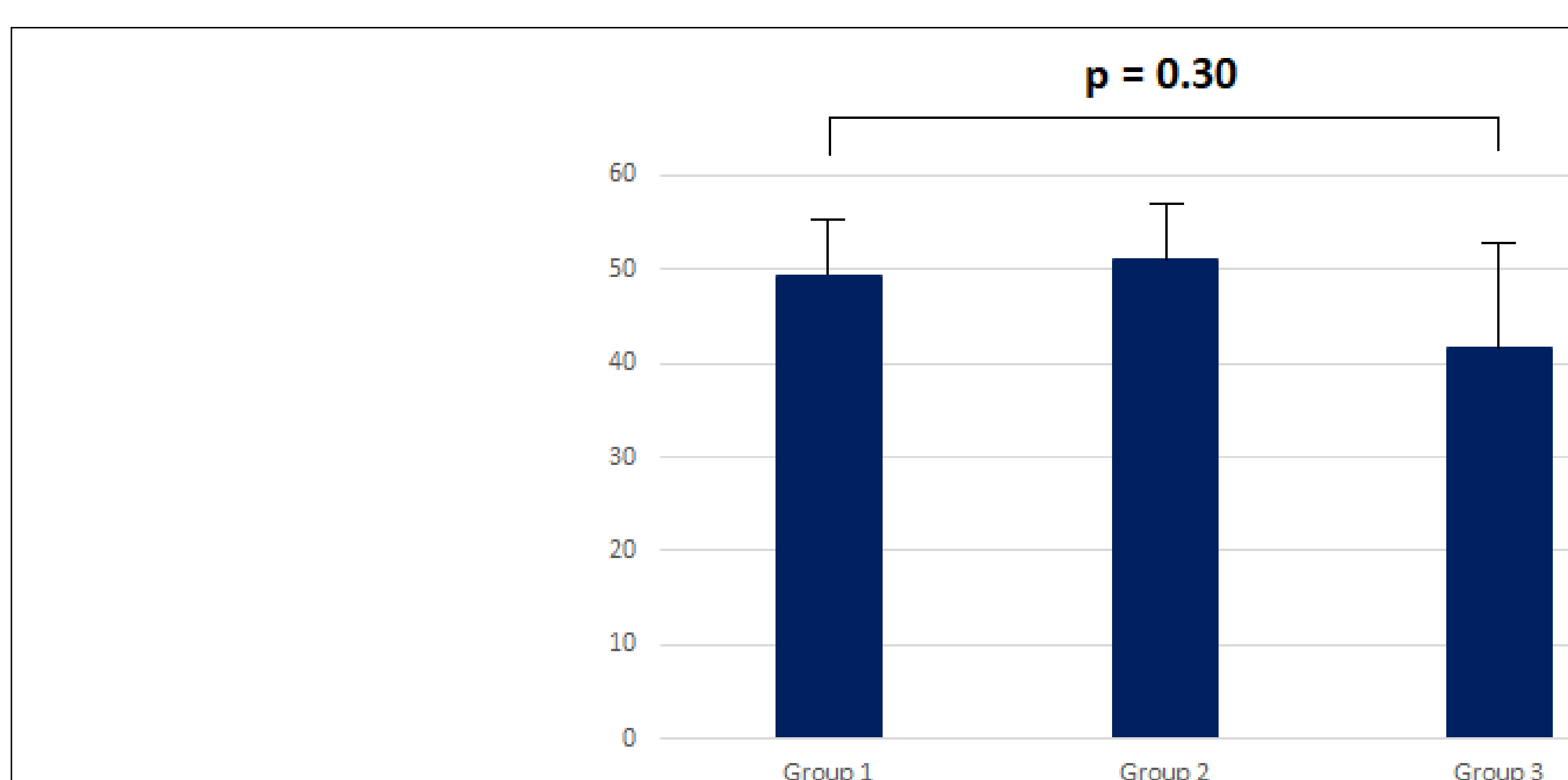

Figure 4. Comparison of meibography as mean percentage of normal glands ( \pm SE).

\section{CONCLUSION}

Dry eye disease is prevalent in preoperative cataract patients. Most patients fit in the mild or moderate category based on the dry eye survey scores. Tear osmolarity and meibomian gland dysfunction correlate with symptom severity and may guide the dysfunction correlate with symptom severity and may guide the
cataract surgeon in pre- and post-operative dry eye treatment planning.

\section{FUTURE DIRECTIONS}

- Determine whether tear osmolarity or MGD correlates best with DES symptoms based on patient-important quality of life parameters

- Determine which preoperative parameters best predict persistent DES symptoms in order to guide prevention

- Explore the interventions which are known to be effective in mproving DE after cataract surgery and determine how they modulate tear osmolarity and MGD

\section{REFERENCES} 1. Choi YJ, Park SY, Jun I, Choi M, Seo KY, Kim EK, Kim TI. Perioperative Ocular
Parameters Associated With Persistent Dry Eye Symptoms After Cataract Surgery Cornea. 2018 Jun;37(6):734-739.

2. Bron AJ, de Paiva CS, Chauhan SK, Bonini S, Gabison EE, Jain S, Knop E, Markoulli M, Ogawa Y, Perez V, Uchino Y, Yokoi N, Zoukhri D, Sullivan DA
DEWS II pathophysiology report. Ocul Surf. 2017 Juli; $15(3): 438-510$

3. Lemp MA, Bron AJ, Baudouin C, Benítez Del Castillo JM, Geffen D, Tauber J . moi: 10.1016/j.ajo.2010.10.032. Epub 2011 Feb 18. ACKNOWLEDGEMENTS

We extend our gratitude to the staff at the Vector Eye Centre. 